\title{
Joining Paths and Dividing Paths: Juiz de Fora, Brazil
}

\author{
Luciane Tasca, Antonio Colchete Filho and Victor Nascimento \\ Department of Architecture and Urbanism, University of Juiz de Fora, Juiz de Fora/MG 36036-330, Brazil
}

\begin{abstract}
The aim of this paper is to present the urban history of Juiz de Fora, a city with some 500,000 inhabitants in southeastern Brazil, and discuss how strategic decisions about the planning and construction of roads and highways can determine ways of life in a city. While paths may integrate landholdings and territories, they may also segregate communities and environments, causing deep rifts in the fabric of urban and land areas. The growth of Juiz de Fora is particularly marked by the construction of paths. This article reviews the local urban history from the establishment of paths in the city, to an analysis of the major impact and benefits they have had, notably on the local economy and demographics, as well as on the conservation of the local environment: Issues that are frequently relegated to a secondary role in the cost-benefit analysis of the city's planning decisions. After analysis of the case study, the authors concluded that citizens should be included on the agenda of the city, from spectators to actors of daily urban life.
\end{abstract}

Key words: Paths, urban form, highways, planning history, Juiz de Fora, Brazil.

\section{Introduction}

Paths are elements of power in the cities. His travels and flows that takes place determines not only the urban form, but also the quality of their spaces and the interrelationship between them.

"Paths are the channels along which the observer customarily, occasionally, or potentially moves. They may be streets, walkways, transit lines, canals and railroads. For many people, these are the predominant elements in their image. People observe the city while moving through it, and along these paths the other environmental elements are arranged and related" [1].

The significance of paths in the city is shown by the obsessive concern of modernist urban planners to open great arteries, prioritizing cars over pedestrians, and the illusion that it will solve traffic problems. The change of focus in modernist view, from pedestrians to cars, led cities to suffer profound changes, with true urban highways tearing the urban fabric and taking hence disruption and disconnection.

This roads-and-traffic-driven approach proved disastrous, because the impact of highway engineering

Corresponding author: Luciane Tasca, Dr., professor, architect and urbanist, research fields: urban planning, social politics and urbanism. E-mail: luciane.tasca@ufjf.edu.br. in urban areas is not only limited to "urban destruction”, but is also related to an opportunity cost, meaning the opportunity lost for creating good urban places, or "disurban creation" [2].

With the growing public awareness, many of these errors are avoided and even undone, like the Lower Manhattan Expressway, the Cheonggyecheon Stream in Seoul or the "Big Dig" in Boston.

In Juiz de Fora, Brazil, is no different. The city emerged along a road and its urban fabric developed with the construction of other roads, which, over time, turned into streets. Presently, a new road is being built across consolidated and densely populated areas, causing deep rifts and segregating communities, including a German colony, where descendants of the builders of Union and Industry Road live, ironically one of the primarily responsible for the current design of the city.

\section{Paths, Means of Transportation and Urban Life}

From colonial times until the beginning of the railways, animal-powered transportation played an important role in moving cargo around Brazil, using the likes of the "donkey troop". With the domestication of animals, people and goods were 
largely transported in urban areas by animal-powered carts or carriages, for a long period of time, this was the predominant means of transportation. However, with the rise of the industrial city, urban spatiality suffered an overturn. Fast changes in the economic, politic, social and cultural spheres led to a new structural organization of the old European cities. Major urban redevelopment projects, such as Haussmann's renovation of Paris between 1840 and 1860, and Barcelona post 1859, highlighted how the physical structure and the ways of functioning of the traditional city, were being shaped by the new demands of the modern city.

With the growth and expansion of cities, followed by electrification of the railways during the last decades of the nineteenth century, it became inevitable and necessary to live with locomotives. The use of trains as means of transportation started to influence changes in urban structures and gradually to replace other means of transportation, such as carriages, carts and animals. Ease of individual transportation combined with the increased movement of people came to define the modern city and shaped its public spaces.

While the centralizing forces of steam power molded the initial patterns of urbanization in the United States, the discovery of electricity and the invention of the inner combustion engine had a dispersive effect. While steam exerted a centripetal force, electrical power came to exert a centrifugal force. The invention of the electric trolley, used for the first time in 1888 in Richmond (Virginia), inverted the so far dominant tendency, allowing the common worker to live further away from the workplace [3].

The result was urban expansion, although an uneven one, in belts, accompanying the tram tracks. The land that was between the "radiuses" formed by the tracks was still inhabited. As such, cities assumed the shape of a star, with its ends aligned to the tram tracks. The cities would maintain this shape until the arrival of the car. Cars gave a new means of mobility to city dwellers and allowed-or encouraged, even - the occupation of regions which were previously inaccessible on the peripheries and outskirts.

According to Jacobs [4], the period during which the car evolved as the everyday means of transportation corresponded precisely to the period in which the ideal of anti-city was architectonically, sociologically, legislatively and financially fomented. It was after the Second World War that a change in the parameters of the road was noticed. The focus of the North American planner, Robert Moses, was no longer concerned with the insertion of the road in the constructed path, rather with the efficiency and safety of car drivers. And, thus, the highway emerged and became the symbol of urban modernization.

In this article, the authors reveal how the establishment of "pathways" in Juiz de Fora led, on the one hand, to the development of the urban fabric and the city as well and, on the other hand, to disruption and disconnection.

\section{Juiz de Fora, a City between Paths}

Occupying a total area of $1,436 \mathrm{~km}^{2}$ [5], the city of Juiz de Fora has been shaped by geomorphological conditioning, by political decisions about the establishment of growth vectors, and by economic strategies to connect the city to other municipalities, such as the Zona da Mata Mineira, as well as to other states, like Rio de Janeiro. Urban occupation, since its origin, developed along the Paraibuna river valley, an historical axis in the movement and exchange of people and goods between Minas Gerais and the ocean port of Rio de Janeiro, and the harbor town of Paraty.

The city's original linear shape restricted its growth. The path traced by the main axis of transportation later suffered when undergoing a widening process, forcing the creation of new, star-shaped pathways, with spaces opening up between corridors of development and extending in projection (Fig. 1). 

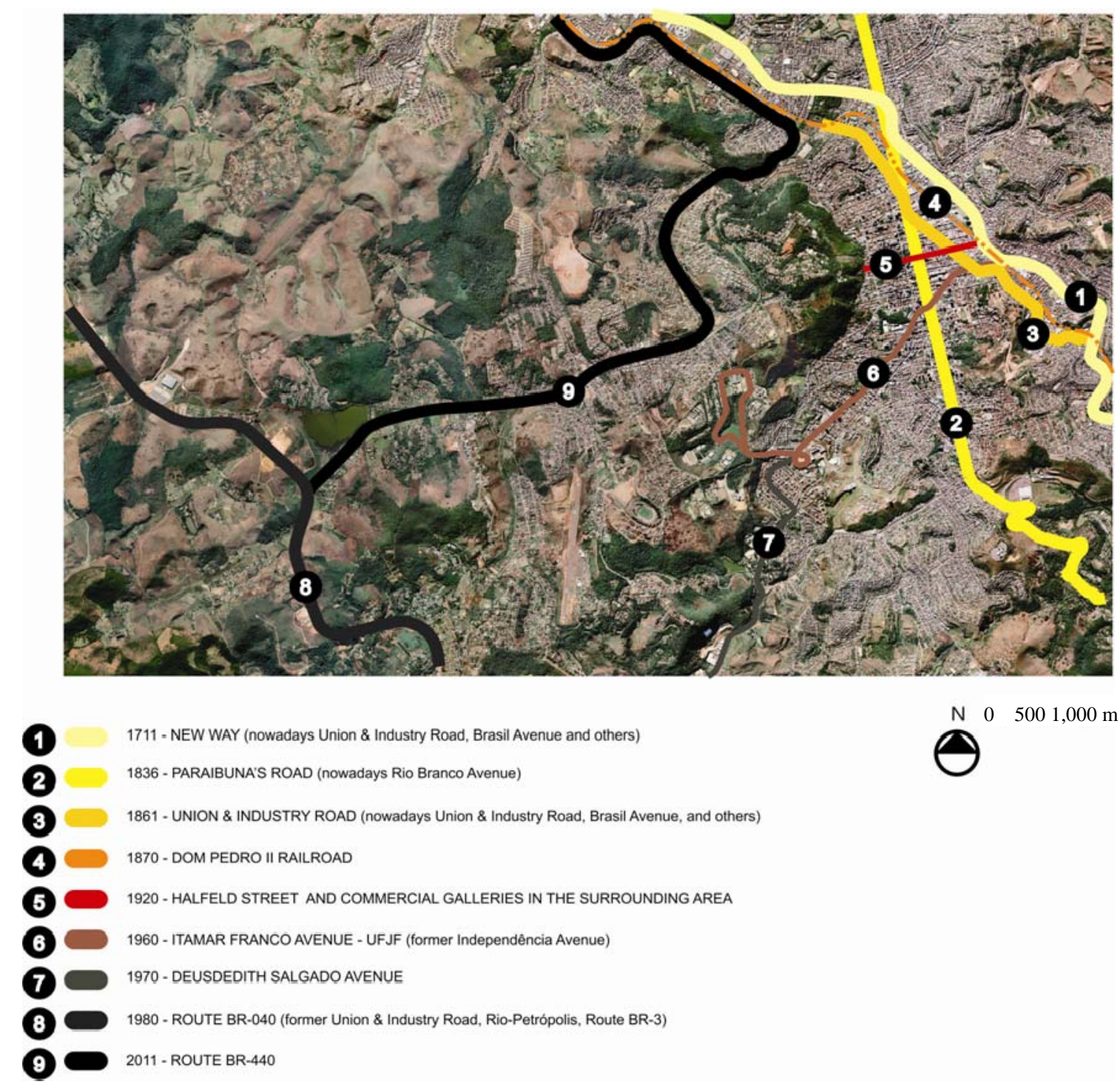

$\mathrm{N} \quad 0 \quad 5001,000 \mathrm{~m}$

Fig. 1 Key paths through Juiz de Fora.

The origins of the city of Juiz de Fora go back to the opening of the "New Way" (Caminho Novo) in 1711. Garcia Rodrigues, who was son of Fernão Dias Paes, a resident of São Paulo city, opened the Caminho Novo, which connected the gold mining region of Minas Gerais to Guanabara state with a journey time of 15 days. Serving for around 200 years as an artery for the transportation of goods and commodities between the port of Rio de Janeiro and the state of Minas Gerais, this road replaced the old axis, known as the "Old Way" [6]. It is worth noting that, up to the origins of Juiz de Fora's urban structuring, the Caminho Novo began to formalize the south/southwest penetration, through the neighborhoods of São Mateus, Cascatinha and Bom Pastor.

In 1830, the government decided to transform the tortuous, century-old, slippery path into a good, navigable road, compatible with needs. A German engineer, called Henrique Guilherme Fernando Halfeld, led the construction of the new road, in 1836. The Paraibuna road ("Estrada do Paraibuna”) actually consisted of a series of modifications to the layout of the Caminho Novo. It can be said that this road 
determined the city's north-south direction which in turn presaged access to areas that today make up the neighborhoods to the north-Grama, Bandeirantes, Bom Clima, among others - and led to the opening in 1970 of what is locally called Garganta do Dilermando, connecting MG-353 Road with the central area, and thus establishing a secondary growth vector in the city. After that, the construction of the Don Pedro II railroad in 1858 and the opening of the Union and Industry Road (Estrada União e Indústria) in 1861, established the right bank of the river as the main articulating axis of the urban development, and the outline of the current central area of the city.

Other important public works at this time included initiatives to improve the city's basic sanitation and hygiene conditions, to pave Halfeld Street (the second street in the city), and to construct canals and bridges, as well as drains and culverts.

In 1888, the Mineira Electricity Company (Companhia Mineira de Eletricidade) was founded, bringing to Juiz de Fora electricity and the consequent industrial prosperity.

The process of occupation of the city resulted in the central area and east portion of Juiz de Fora having a more compact configuration, while other sections remain very sparse. The Urban Development Master Plan (1996) [7] shows that, in addition to empty intra-urban spaces within the city's perimeter, there are some 37,000 vacant lots with an area smaller than $5,000 \mathrm{~m}^{2}$ (according to the 1995 property tax register). Thus was demonstrated potential for growth and densification of the urban sprawl, which still prevails today. However, because of its peculiar characteristics, the city's capacity for demographic absorption differs between urban sectors, establishing its social-spatial feature, planning actions were prioritized in areas of private interest at the expense of addressing existing problems in the peri-urban areas, thereby playing out the capitalist logic that embodies the difference in ownership of wealth, as Tasca [8] stated.

There were new and profound changes that were taking place at a regional level during the 1950s which exerted an influence on Juiz de Fora as a mid-way point on the highway. What is apparent throughout this process is that, as Tasca [8] maintained, these were road construction projects that were guided by a common vision of the city, with the same objectives that were based on meeting expectations of the land market, real estate, as well as the construction industry. These projects appealed in particular to road users, however, in considering how roads should be structured, they encouraged the reorganization of the urban fabric. The central neighborhoods, which benefited from the structure of the urban fabric created in downtown Juiz de Fora, continued to receive greater investment compared to the neighborhoods that were populated by predominately low-income groups, and made minor gains. Thus, the city's popular feature was maintained: the network of roadways essentially deciding who can afford to live where within Juiz de Fora.

Nowadays a new path is been built, the BR- 440 . This federal road will connect, via the city, the two main roads of BR-040 and BR-267 which both pass through Juiz de Fora.

While these paths may differ greatly from one to the other, they all continue to play a part in the everyday life of Juiz de Fora-ranging as they do from highways to boulevards, streets, sidewalks and malls. All of these paths strengthen the city, as well as hem it in.

\section{Road, Avenue and Street (and Boardwalks and Galleries): The Urban Net}

\subsection{BR-040}

Running the length of some 1,172 km, the BR-040 leaves Brasília, and has as passing different points before ending in the city of Rio de Janeiro. During the 1980s, following the modernization of BR-040, Juiz de Fora experienced significant growth in its steel industry, and more recently, in the local car industry when, in 1996, Mercedes-Benz established a major 
plant there. Nowadays, along the section that runs closest to the city, this road-dangerously—serves as an everyday commuter belt, as it connects neighborhoods, built-up service areas and the industrial sector with access roads into Juiz de Fora.

\subsection{BR-440}

The BR-440 will have three overpasses, one at the exit for the BR-040. However, the project for constructing this road is more than 30 years old. A lack of environmental and socio-economic impact assessments resulted in various leaders from different sectors of society to organize a protest group, popularly called the "Say No to BR-440" group (“Comitê Diga Não à BR-440”). Members of the group include representatives of civil society organizations, resident associations, local academics and architects, among others. Among the issues being contended by them are that no construction business plan exists, while the master plan for urban development does not forecast the building of this road. Moreover, it is taken for granted that there are potential problems with the local water supply, expansion of the road network, as well as the likely appropriation of property and land from dozens of local residents. Popular mobilization is promoted by the protest group generated results. The constructions of the highway are stopped due to budget problems and design.

\subsection{Rio Branco Avenue}

Development of Barão do Rio Branco Avenue began in 1836, on the old Paraibuna Road with the aim of creating an alternative route to Caminho Novo. This road directed the growth of Juiz de Fora into an area where the topography was less rugged, with characteristics of the surrounding valley. Once it became a regional road used to regulate traffic flow, it was renamed Main Street (Rua Principal), and later again titled Direita Street, when the town of Santo Antônio do Paraibuna was elevated to city status, up until it was changed to the current name. It is considered in Brazil to be one of the longest avenues that run in a straight line, extending to a total of 6.4 $\mathrm{km}$, of which $5.7 \mathrm{~km}$ are in a straight line. Redirecting the flow of the Paraibuna river in 1940 not only contributed to invigorating the city center, but ended the flooding which ravaged the local area, and generated further clean-up projects. By the 1960s and 1970s, the avenue was becoming denser as it extended in height, with vertical elevations. Come 1970, it also extended to the north region with the opening of the road, effectively cutting through the hill that had previously prevented expansion. At present, the avenue's boundaries are marked by Garganta do Dilermando and Alto dos Passos, one of the city's historic neighborhoods, where it runs along what was the old Paraibuna's road. Nowadays, with a central reservation exclusively for buses, the two-way Rio Branco Avenue represents the most majestic street in the city, and experiences considerable movement of people and vehicles, notably where it meets with Halfeld Street.

\subsection{Halfeld Street}

Halfeld Street's most marked characteristic is an overlapping of periods in the city's history, as it creates an axis of movement while also having an important role in local culture and heritage. This path, which experiences heavy flows of people, is demarcated by the central train station and a hill known as Morro do Imperador. At stages, it is a street in which people and cars travel together, at others, it becomes an extension of the square by the train station, and then a pedestrianized shopping area, regarded as the heart of the city, which empties into a landscaped park enjoyed by many, before continuing up towards the mountain, where vehicles can rejoin it. The pedestrianized shopping area, besides being a place where people go to meet or relax, also serves as a political and religious center for the city. Along the length of this path, with all its physical and functional diversity, Halfeld Street can be considered the center of downtown. 


\subsection{Malls and Galleries}

Aside the flow and movement of pedestrians in and around the galleries and mall areas, these places, along with the city's squares, are renowned places for where people shop and go to relax [9]. The galleries, built from the 1920s onwards, form a network of paths that, as Abdalla [10] maintained, significantly change the layout of buildings, increase the land value, and offer pedestrians different ways to get between main streets. Another aide to movement of people in this network of paths is the introduction from 1970 of pedestrianized walkways. Together with the galleries, they form spaces that accommodate a great variety of uses, appropriations and pedestrian flows. They are in many ways the space that truly supports the development of urban life and culture, characterizing so well the center and the city of Juiz de Fora itself [11]. The pedestrianized walkways, being essentially public spaces, have become the representative urban image of this city, to better understand the role that such public spaces have in the formation and shaping of contemporary everyday life. As such, Paula [12] concludes that the dynamic of the gallery and network of pedestrianized walkways in the central area of cities contribute to the maintenance of their very centrality and vitality. These are much valued qualities in an urban space, not least in Juiz de Fora where this set of paths is so unique.

\section{Conclusions}

In the modern world, paths constitute the link between different realities. In the beginning, they connected the fields to the city; later, one city to another. In the cities, they promote growth, as well as the constant acceleration of fluxes, which is a demand of modern life. Always conditioned by the available means of transportation, paths led people and wealth worldwide. As time passed, the means of transportation changed, and with them, the paths also changed. The arrival of the car meant that paths were multiplied, in quantity and dimension. The ease of movement, individual and fast, allowed the indiscriminate propagation of paths all over, turning the city into a bigger urban territory. And, in the same way that the city expanded, the car would also multiply, sometimes disproportionately.

If, in the old days, as seen in the urban history of Juiz de Fora, it was favorable that the roads went through the middle of the city, bringing people and goods directly into its nucleus, nowadays this situation is no longer desirable. The significant rise in the flow of people, goods and, consequently, vehicles, inverted this situation. Having less impact would be the construction of a road ring, going around the city, or the reactivation of rail transportation (for cargo and people).

The analysis of the BR-440 shows that the highway construction is part of an anachronistic vision of progress, which may be illustrated by Robert Moses's maxim: "When you operate in an overbuilt metropolis, you have to hack your way with a meat ax" [13].

The region crossed by the highway, besides the historical symbolism connected to German settlers, is part of a reserve area for expansion of the city, characterized in the master plan for urban development. According to it, the region is lacking in infrastructure and services, especially leisure. Thus, the perspective adopted in this article reveals that the high social cost impact of a highway within a consolidated city region exceeds its benefits. Many mistakes have been committed. It is time to put in the balance the pros and cons and include citizens in the agenda for discussion. The lost opportunity to create good urban spaces has to be faced, sooner or later. And if people, visions and institutions of the city create the highway, only they can create something better.

\section{Acknowledgments}

The authors would like to thank to the CNPQ (National Counsel of Technological and Scientific Development), UFJF (Federal University of Juiz de 
Fora) and FCT/UFJF (Technology Center Foundation) to support the research.

\section{References}

[1] K. Lynch, The Image of the City, MIT Press, Cambridge, 1960, p. 47.

[2] S. Marshall, Streets and Patterns, Spon Press, New York, 2005, pp. 8-9.

[3] J.J. Palen, The Urban World, McGraw-Hill Inc., New York, 1975.

[4] J. Jacobs, The Death and Life of Great American Cities, Vintage Books, New York, 1961.

[5] Brazilian Institute of Geographic and Statistic Home Page, http://www.ibge.gov.br/cidadesat/painel/painel.php?codm un=313670 (accessed May 15, 2012).

[6] M.C. Carvalho, Paths from Rio to Juiz de Fora, M. Carrilho Arquitetos, Rio de Janeiro, 2010. (in Portuguese)

[7] Proposal for Master Plan of Juiz de Fora, Office of Planning and Research, PDDU (Prefeitura de Juiz de Fora), Funalfa Edições, Juiz de Fora, 1996. (in Portuguese)
[8] L. Tasca, The contradictions and complementarities in urban laws of Juiz de Fora: From plans to intervention projects, Ph.D. Thesis, Federal University of Rio de Janeiro, Rio de Janeiro, 2010. (in Portuguese)

[9] A.C. Filho, V. Nascimento, Paths joining and separating: the controversial BR-440 in Juiz de Fora, Brazil, in: EURA Conference 2011: Cities without Limits, Copenhagen, Denmark, June 2011.

[10] J.G.F. Abdalla, Multivalency of the Architecture of the Galleries of Juiz de Fora: Fascination and Identity Between the Public and Private, Research report, Juiz de Fora, 1996, p. 68. (in Portuguese)

[11] F. Fonseca, The pedestrianized walkways and its importance to the urban quality in the central area of Juiz de Fora, Master Dissertation, Federal University of Juiz de Fora, Juiz de Fora, 2012. (in Portuguese)

[12] F.B.R. Paula, Passages in a network: the dynamics of commercial galleries and pedestrianized walkways in downtown Juiz de Fora and Buenos Aires, Master Dissertation, Federal University of Rio de Janeiro, Rio de Janeiro, 2008. (in Portuguese)

[13] M. Berman, All That Is Solid Melts into Air, Simon and Schuster, New York, 1982, p. 290. 